\title{
A Method for Assessing Website Communicative Efficacy Using a Semantic Annotation Tool
}

\author{
Nadzeya Kiyavitskaya ${ }^{1}$, Nicola Zeni ${ }^{2}$, Cristina Coulleri $^{2}$, and Luisa Mich ${ }^{2}$ \\ ${ }^{1}$ Dept. of Information Engineering and Computer Science, University of Trento, Italy \\ nadzeya@disi.unitn. it \\ ${ }^{2}$ Dept. of Computer and Management Sciences, University of Trento, Italy \\ \{nicola.zeni, luisa.mich, cristina.coulleri\}@unitn.it
}

\begin{abstract}
Evaluation of the communicative efficacy of a website is important in the context of an organization communication strategy. To address this issue, we propose a systematic method and a tool that supports it. The tool is based on a general-purpose semantic annotation framework. The application and feasibility of the method are introduced through a case study where it was used to compare the communicative efficacy of a set of tourist destination websites.
\end{abstract}

Keywords: communicative efficacy, website content, communication strategy, tool support, Cerno.

\section{Introduction}

Communication has been investigated in different disciplines: rhetoric, psychology, mathematics, sociology, anthropology, and many others. Information theory [19] and communication theory as specific disciplines have drawn a widespread interest since the inception of new communication channels and devices. Thus, we have a large variety of areas and contributions related to communication principles and theories. In particular, computer science has been investigating communication issues in the context of such disciplines as artificial intelligence, natural language processing, human computer interface, knowledge management, addressing also human-side aspects apart from those considered first, that included, for example, coding. Among them, an important role is given to the communication efficacy $(C E)$ that is the capacity of communicating to accomplish a desired goal. CE has been investigated, for instance, for communication in the context of collaborative interaction tools, where "the CE of the environment is determined based on how quickly participants are able to accomplish the task at hand" [5]. Other studies focused on the analysis of the pragmatics of communication [10,28], more specifically, on the effect of messages in terms of actions following an utterance or linguistic act [1]. Websites are eminently communicative environments, and their content is critical to fulfill business goals of a company and for its communication strategy [24].

In order to identify a systematic way to evaluate the $\mathrm{CE}$ of a website, we first start from the fundamental principles of communication. In the classical rhetoric of Aristotle a discourse can be given to "docere, delectare, flectere", that is to instruct the audience, gain their goodwill, and arouse their emotions [7]. The modern communication 
theory identifies four fundamental objectives: control, motivation, information, emotional expression $[18,21]$. Websites play a relevant role to support all these objectives, which are strongly related to on-line corporate communication, and in particular to marketing communication strategy [24]. Though there are a variety of studies and models for website quality (see, among the others, $[13,15,25]$ ), the evaluation process based on these models is not straightforward. Moreover, little methodological and tool support was developed so far in addressing the specific issue of CE. Also, from the business point of view, web analytics are used to measure the success of a web site, while our goal is to address $\mathrm{CE}$ as a design method, as an ex-ante issue. In this respect, $\mathrm{CE}$ requires as necessary conditions that: (a) the website functions correctly and (b) the website contains all the necessary information to support the goals related to the communication strategy. Our work focuses the second aspect of the CE, i.e., we develop a method to ensure that the website contains all the necessary information to accomplish the business model's goals in the context of the corporate communication. We assume the fundamental hypothesis of semiotics [2] which distinguishes three levels of the message analysis: syntax, semantics, and pragmatics; where the third level is a function of the others. In fact, in the first instance, the effect of a message depends on its correctness (syntax) and the content informativeness (semantics). To this end, the task that we address in this work is measuring the content informativeness dimension. In order to do this, we suggest adopting semantic annotation (SA) tools developed to identify relevant categories in text, video or audio content. We elaborate a systematic approach for evaluating the CE based on a SA framework called Cerno [9]. For a preliminary validation of the method we considered a set of 13 websites of local Tourist Boards in the Italian province of Trentino: Aziende di Promozione Turistica di ambito (A.P.T.). Some results of this study were published in [8], where we illustrated Cerno and its performances in terms of recall and precision. This work introduces the CE evaluation method, which steps have been defined based on the experience maturated since then.

The paper is structured as follows: section 2 describes our approach of evaluating the $\mathrm{CE}$ of websites; section 3 illustrates the application of the proposed method on a case study analyzing the $\mathrm{CE}$ of tourist destination websites; and the conclusions of are drawn in section 4 .

\section{Our Approach}

Our starting assumption for evaluating the CE of a website is that the efficacy of communication depends on the content informativeness, and in particular on the breadth of the knowledge coverage. This characteristic implies the need in identification of the pieces of information pertinent to the website goals in its content. This task can be addressed by $S A$ of document text, which explicitly assigns semantics to text fragments relevant to a particular annotation goal.

Based on these assumptions, we suggest an evaluation process that consists of the following steps:

1. Analyze the business model of the company by identifying its mission and its management strategies.

2. Identify the role of the website in the business model. 
3. Based on the identified objectives of the website, understand how the website should support this role in terms of its content.

4. Derive the conceptual model for SA using the list of content categories and concepts.

5. Fulfill the SA in order to find all content fragments related to the entities of the conceptual model.

6. Use the results of the SA to calculate some indexes to evaluate the CE of the websites.

The following subsections elaborate each step of the process.

1. Identification of the business model. The CE can only be estimated within a specific communication environment, because it requires understanding the goals of the communication. In other words, our first concern must be to identify the mission that an organization is trying to achieve and its business model.

2. Identification of the website role in the business model. Having derived the organization's strategies and business model, we need to understand the role of the website within this model, i.e., which goals is the website supposed to contribute to.

3. Identification of relevant content categories. To realize the goals derived from the business model of the organization, the website has to provide appropriate content, making the user take an action that the organization is interested in. Thus, our next step is to analyze the goals of the website and identify a list of key categories that must be present on it to contribute to its CE.

4. Derivation of the conceptual model. When the key categories are provided, the next step is to specify them by eliciting more specific concepts and defining a domain conceptual model. For example, the concept of Geography is a generic category and can be extended with a lot of related terms based a dictionary or a thesaurus like WordNet [29]. In order to limit the scope of related terms, we suggest asking the domain experts to filter candidate concepts by selecting only those relevant to the website strategy.

5. Semantic annotation based on the derived model. The conceptual model built on the previous step should guide the SA process. There are many SA approaches and tools available (a detailed classification of such tools can be found in [20]). However, some tools cannot be applied for the evaluation of websites. For example, machine-learning methods require essential amount of training data in order to provide reliable results, whereas it is not feasible to expect much training data provided from a single site. Wrapper induction methods are not applicable since they rely on the regularity of HTML format, on which the annotation rules are based. Therefore, we suggest using one of the rule-based approaches. In the perspective of this work, i.e., tourist destination websites, the domain knowledge corresponds to the business strategies materialized in the website. Starting from these strategies, a domain conceptual model must be derived. One of such model-driven annotation tools based on a comprehensive SA framework is Cerno [9]. In Cerno, the conceptual model obtained from domain experts must be then converted into an annotation schema, i.e., the list of semantic categories with their annotation rules. After that, the annotation process can be executed. 
6. Analysis of the annotation results based on the efficacy measures. The results of the SA can be used as an input for calculation of quantitative measures of CE. The most basic index is to calculate the total number of annotations identified for each category and check which categories are well-covered and which are underrepresented. This index can be then elaborated into more complicated metrics [3]:

- The evaluation according to a hierarchy inside of the conceptual model. Every concept can be assigned a weight (w) based on its hierarchical level of the conceptual model. The idea is to assign smaller weights to the deeper levels, while weight higher top level concepts. The final result is the sum of the number of annotations $\left(\mathrm{Na}_{i}\right)$ for each $i$-th concept multiplied by its corresponding weight.

- The evaluation based on the website structure hierarchy. This metric takes into account the hierarchy structure of the website. For example, the information found on its Home page can be given a greater weight compared to the information that is provided on the internal pages, assigning a weight according to the hierarchy level of the annotations.

- The evaluation based on the number of keywords. Instead of using a SA tool to provide the quantitative data on the content coverage, one can use a list of keywords related to the concepts of interest.

- The evaluation based on the relevance of HTML tags. When fulfilling the SA, one can take into account the information about HTML tags where the annotations were found. For instance, the heading like $\langle$ h 1$\rangle$, $<t i t l e>$, can be given a higher score than the text found in $<\mathrm{p}>$ tags.

- The evaluation based on the user profile. This measure combines two things: the information on the profile of the user as well as the information on the needs of the user. One solution to obtain the profile data is to use sociodemographic reports, as for instance in [23].

Formulas for the first four metrics are represented by the sum of annotations which are multiplied by weights assigned according to the suggested evaluation aspect, i.e., position in the hierarchy of the conceptual model, position in the hierarchy of the website, relevance of the keywords, or relevance of the HTML tags:

$$
C E=\sum_{i=1}^{n} \sum_{j=1}^{m} N a_{i j} w_{j}
$$

To express the last metric we can use the following function:

$$
C E=f(\text { user profile, user needs) }
$$

where a user profile could be for example defined in the set \{student, manager, teacher, employed, unemployed, elderly, family $\}$; user needs could be defined as Accommodation $=\{$ hotel, camping, $\mathrm{B} \& \mathrm{~B}$, residence, apartment $\}$. In this case, weight distribution depends on the profile and needs of the users. 
All these measures require a preliminary selection of weights. This selection must be realized by domain experts together with web engineers and is not trivial.

\section{Case Study of Alpine Tourist Destination Websites}

This case study was run within a larger project of the eTourism group of University of Trento [6] which aim was to investigate the tourism models of Trentino (http://www.provincia.tn.it/) as an alpine destination. The economy of Trentino which is part of the Italian autonomous region Trentino Alto-Adige Suedtirol - is mainly based on tourism, and the territory is organized in fifteen agencies responsible for local administration and promotion [11]. We choose the Local Tourist Boards in Trentino because they are highly uniform as regards their mission and goals unlike agencies of promotion at higher level (national and regional). Moreover, we found a reasonable number of them, i.e. 15 (this number refers to the situation until year 2008), which allows carrying out an accurate analysis of the sites. The following subsections illustrate application of the CE evaluation method.

1. Business model identification. Tourism is a principal source of income in many areas of the Trentino Dolomites, and therefore, the mission of the Tourist Boards in this area is marketing and promotion of local tourist destinations. In particular, the eTourism group was interested in evaluating the efficacy of the Tourist Boards in promoting these alpine destinations among international visitors. To address this task, we need to assess the quality of the communication realized by the Tourist Boards to accomplish this goal.

2. Identification of the website role in the business model. The communication for promoting the alpine destinations is realized through the official websites of 15 Tourist Boards. Considering the international target of tourism offer, one of the main requirements of our investigation was the presence of English versions of the websites. Only 13 websites satisfy such a requirement. Thus, we have to extract the English-language content of the websites and analyze how comprehensively the strategic goals of the Tourist Boards are represented there.

3. Identification of relevant content categories. In order to derive a list of key categories that must be covered by a Tourist Board website to be effective, we referred to the notion of tourist destination, which is defined as a place of travel that tourists wish to visit due to its natural or artificial attractions. A tourist destination is characterized by the following factors [13]:

- a well-defined geographic area with specific borders and a territorial identity;

- presence of a variety of operators with different visions and objectives which requires a shared strategy in promoting a local offer;

- understanding of the nature of a potential demand for the tourist products offered;

- awareness of the need to balance tourist use of local resources according to ecological, environmental and community regulations. 
Among the operators involved in generation of the tourist product are: Hosting structures, Restaurants, Commerce, Handicrafts, Agriculture, Entertainment, Cultural institutions, Sports activities, Free-time, Public boards, Transportation, Public services.

All these factors and operators embrace a list of key categories important for promoting a tourist destination. The nature of the destination is another issue to take into account. There exist many various types of destinations, and concepts relevant for each type differ or need to be defined at different level of details [14]. In the context of our case study, alpine destinations are characterized by specific sport activities (skiing, snowboarding, hiking, mountain biking) and lodging facilities (hotel, B\&B, garni, gasthaus) that visitors are interested in. Whereas for a religious destination, for instance, sports do not play an important role and an accommodation could be arranged in a convent. Therefore, in the next step we elaborate the key categories based on our destination type.

4. Derivation of the conceptual model. In order to develop a conceptual model for CE of an alpine destination, we asked the tourist experts to select a subset of high-level categories and more specific concepts relevant for its strategies. The resulting list includes the following concepts: accommodation (hotels, campings, apartments for rent), catering places (restaurants, local food), sports (possibility to do various sport activities, competitions, courses, facilities), transportation (how to reach a destination by any transportation means, timetables, terminals), culture and history (artistic heritage, places to visit, cultural events, local traditions, holidays, costumes), and medicine (medical services and treatments of the resort). See the extended description of these categories in Table 1.

Table 1. Topics related to the CE of Tourist Board Websites for an alpine destination

\begin{tabular}{|l|l|l|}
\hline Category & Key concepts & Description \\
\hline Geography & $\begin{array}{l}\text { Climate, Weather } \\
\text { predictions, Land } \\
\text { Formation, Lakes and } \\
\text { Rivers, Landscape }\end{array}$ & $\begin{array}{l}\text { Comprises characteristics of the landscape } \\
\text { (mountain, lakes, plateaus), or geologic features } \\
\text { (type of the rocks), characteristics of the } \\
\text { environment (natural resources, parks, protected } \\
\text { zones, biotopes) and climate (temperature, } \\
\text { number of sunny days, precipitations, quality of } \\
\text { the air, altitude) }\end{array}$ \\
\hline Local products & $\begin{array}{l}\text { Local handcrafting, } \\
\text { Agricultural products, } \\
\text { Gastronomy }\end{array}$ & $\begin{array}{l}\text { Concerns all aspects that differentiate the } \\
\text { production of one destination from the others: } \\
\text { typical products of local agriculture, farming, } \\
\text { and gastronomy (wine, cheese, sausage), or } \\
\text { products related to forest - (wood, mushrooms, } \\
\text { flowers). Local handicraft products are also } \\
\text { important (sculptures, weaving, embroidery, } \\
\text { etc.). Includes also markets and fairs. }\end{array}$ \\
\hline
\end{tabular}


Table 1. (Continued)

\begin{tabular}{|c|c|c|}
\hline Culture & $\begin{array}{l}\text { Traditions and } \\
\text { customs, Local history } \\
\text { Festivals, Population, } \\
\text { Cultural institutions } \\
\text { and associations, } \\
\text { Libraries, Cinemas, } \\
\text { Local literature, Local } \\
\text { prominent people }\end{array}$ & $\begin{array}{l}\text { Description of historical aspects related to the } \\
\text { origins of the local population, ancient } \\
\text { institutions of local governing (laws, municipal } \\
\text { government, etc.) Other characteristics are } \\
\text { folklore manifestations, customs and traditions } \\
\text { related to particular periods of the year (e.g., } \\
\text { carnival, Christmas). It includes also cultural } \\
\text { associations (choruses, bands, etc.), libraries, } \\
\text { reading-rooms, cinemas. Historical and } \\
\text { contemporary personalities of the area, such as } \\
\text { writers, photographers, mountain climbers. }\end{array}$ \\
\hline Artistic Heritage & $\begin{array}{l}\text { Places to visit: } \\
\text { museums, castles, } \\
\text { Tickets, fees, guides }\end{array}$ & $\begin{array}{l}\text { Artistic heritage involves all that a tourist can } \\
\text { visit or see in a destination; among these are: } \\
\text { churches, castles, museums, ruins, castles, etc. }\end{array}$ \\
\hline Sport & $\begin{array}{l}\text { Sporting events, Sport } \\
\text { infrastructure, Sport } \\
\text { disciplines }\end{array}$ & $\begin{array}{l}\text { Usually, it is distinguished between winter and } \\
\text { summer sports. Among winter sports there are } \\
\text { all types of snow activities (e.g. downhill, cross } \\
\text { country skiing, snowboarding, etc.). Summer } \\
\text { activities include excursions, climbing, Nordic } \\
\text { walking, jogging, mountain bike, paragliding, } \\
\text { etc. Other sports relate to this category, such as } \\
\text { those practicable using special infrastructure } \\
\text { (swimming pools, gold fields from golf, etc.). } \\
\text { Relevant information is rental stations of sport } \\
\text { equipment, training possibilities, enrollment to } \\
\text { specific initiatives (alpine guides). Includes sport } \\
\text { manifestations as well (e.g., marathon races). }\end{array}$ \\
\hline Accommodation & $\begin{array}{l}\text { Places to stay, How to } \\
\text { book, How to arrive, } \\
\text { Prices, Availability }\end{array}$ & $\begin{array}{l}\text { Comprises all types of accommodation (hotel, } \\
\text { pension, residence, bed and breakfast, rooms, } \\
\text { campings, hostels, garni, hospitality in family). } \\
\text { Apart from this, relevant information is } \\
\text { modalities to make a reservation, offers, } \\
\text { discount packages, prices must be indicated. }\end{array}$ \\
\hline $\begin{array}{l}\text { Food and } \\
\text { refreshment }\end{array}$ & $\begin{array}{l}\text { Places to eat, Dishes, } \\
\text { Degustation, Time } \\
\text { tables, How to book }\end{array}$ & $\begin{array}{l}\text { Concerns various eating structures (restaurant, } \\
\text { pizzeria, bar, malga), typical dishes, initiatives } \\
\text { related to tasting of local products. Relevant } \\
\text { information includes restaurants' opening hours, } \\
\text { how to reach the place, how to make a } \\
\text { reservation of a lunch, how to get to a restaurant. }\end{array}$ \\
\hline Wellness & $\begin{array}{l}\text { Wellness centers, } \\
\text { Wellness services }\end{array}$ & $\begin{array}{l}\text { Often, the wellness structures are present in } \\
\text { hotels or thermal centers. Those include Turkish } \\
\text { bath, sauna, massages, diets, gymnastics, beauty } \\
\text { treatments. }\end{array}$ \\
\hline Services & $\begin{array}{l}\text { Transport, schedules, } \\
\text { Information offices, } \\
\text { Terminals, stations, } \\
\text { airports, Travel } \\
\text { agencies }\end{array}$ & $\begin{array}{l}\text { Means of transports available in the region: } \\
\text { buses, shuttles from the airport, ski-buses, trains; } \\
\text { routes, timetables, parking areas, the distances } \\
\text { from highways, railway and coach stations. } \\
\text { Tourist information offices, Tourist boards and } \\
\text { travel agencies. }\end{array}$ \\
\hline
\end{tabular}


5. Semantic annotation based on the derived model. Having derived a list of concepts of interest, we fulfilled the SA of the English-language content.

In order to populate the components of Cerno with annotation rules, the initial schema provided by the domain experts was expanded semi-automatically using definitions and synonyms provided by WordNet [29] database and the on-line Thesaurus [16]. The total number of annotation rules collected was 507.

To download and save the website content, we used an automatic tool called WebExtractor [27]. After that, we converted the websites from their format (HTML, PHP, or others) into textual form using Detagger [4], a tool which removes markups and scripts from the documents. As a result, we obtained a set of 11742 paragraphs of plain text and performed the SA of these paragraphs using Cerno. See a fragment of the annotated content of a website in Fig. 1. The technical details of the annotation process setup and evaluation can be found in [8].

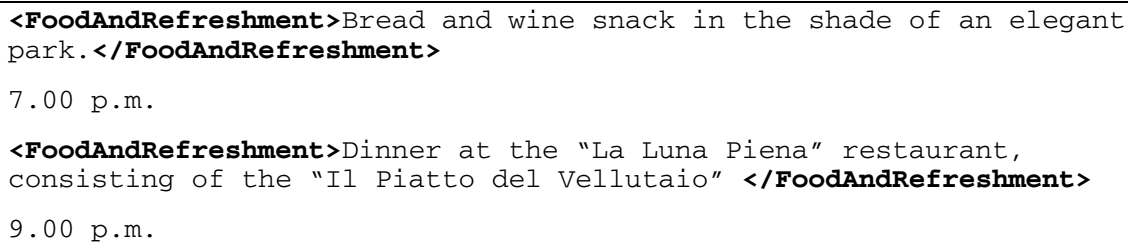

<ArtisticHeritage>Museo del Pianoforte Antico: guided visit and concert proposed within the "Museum Nights" programme on the 3, 10, 17 and 24 of August.</ArtisticHeritage>

Fig. 1. Example of the annotated content of the website

6. Analysis of the annotation results. When the annotation process was completed, we calculated the total number of all the identified phrases relevant to varied categories, shown in Table 2. To provide a qualitative diagram of these results, Fig. 2 displays the coverage of different categories by all websites. From the both figure and table, we observe that the best total score was estimated for the website of A.P.T. Altopiano di Pinè e valle di Cembra. Moreover, this website also covers all the categories with at least one text fragment, which means that the CE was high both in terms of overall breadth and depth of relevant information provided.

The results revealed that the best-covered category among all others was Geography. The total sum of Geography-related annotation was 185 . In fact, all of the considered websites include a page presenting the destination, which normally contains many geography-related terms, like "mountain", "valley", "alpine" and others. The highest scores were demonstrated by A.P.T. dell'Altopiano di Pinè e valle di Cembra (26) and A.P.T. San Martino di Castrozza, Primiero e Vanoi (24). Another well-represented category was Sport, whose total sum of annotations was 78. This result is also not surprising, given that the major focus of promotion of Alpine destinations is different kinds of mountain sport activities. The least covered category was Wellness. Its total count of annotations was 9. In fact, only few websites provided the information about wellness facilities, like beauty 
centers, fitness courses, or massages. The site that contained most information about this category was A.P.T. Terme di Comano-Dolomiti di Brenta (4). Other under-represented category was Food and Refreshment, where the total count was 31 and only 10 of 13 websites provided related information. As the matter of fact, the information about places to eat was not covered by those versions of the website.

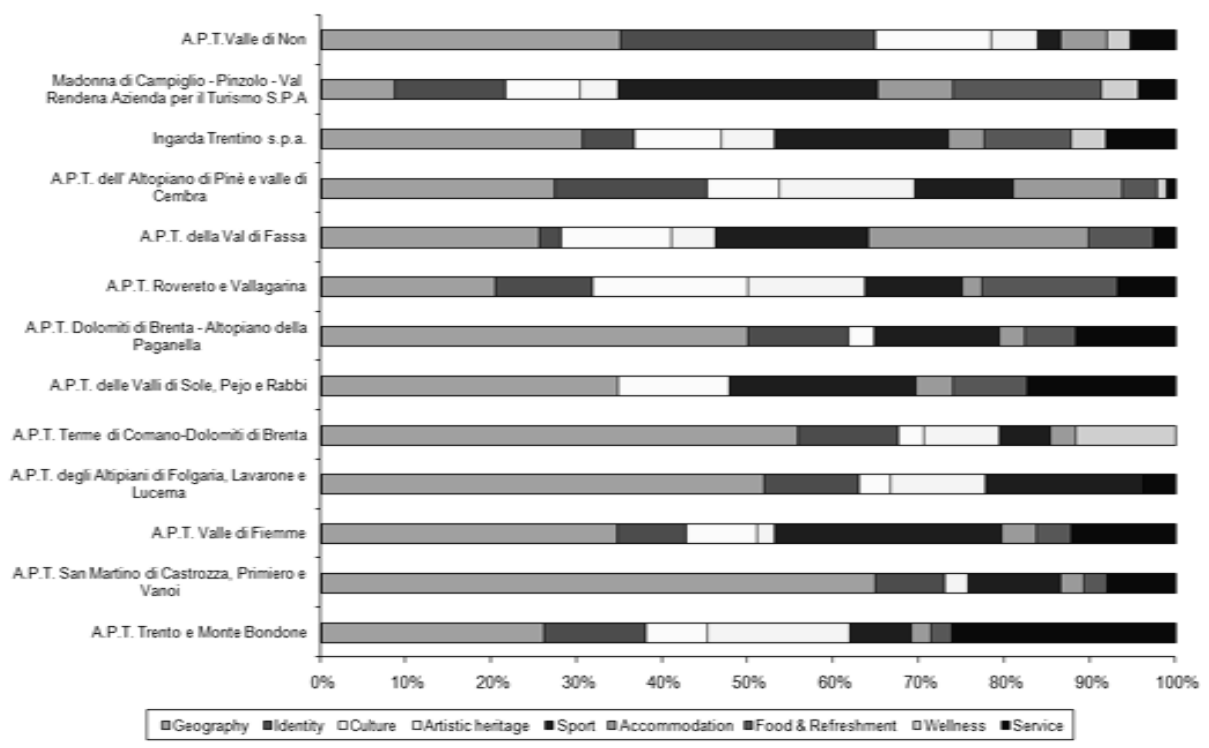

Fig. 2. Diagram of coverage by all categories by 13 websites

The results showed that the site of A.P.T. dell' Altopiano di Pinè e valle di Cembra had the best CE; it not only has the greatest total count of annotations, but also represented all of the categories. The lowest CE in terms of both breadth of knowledge coverage and extent to which this knowledge is elaborated (see section 2) was shown by the following sites: (a) A.P.T. delle Valli di Sole, Pejo e Rabbi with a total count equal to 23 and three categories are not represented at all; (b) A.P.T. degli Altipiani di Folgaria, Lavarone e Lucerna with a total count equal to 27 and three categories that are not represented. One website also demonstrated a low total score equal to 23 (Madonna di Campiglio - Pinzolo - Val Rendena Azienda per il Turismo S.P.A.); however, all the categories are represented by this site at least once. Consequently, this website demonstrated good breadth coverage of related information, but poor elaboration of this information.

The obtained results can be used to provide some recommendations to the Tourist Boards regarding the ways to improve their website content in order to achieve a better CE. For example, the importance of several categories, especially Wellness, Food and Refreshment, and Accommodation, was underestimated by the website developers. Therefore, more information related to these categories 
must be provided. The overall representation of relevant information was not balanced. We found out that the majority of websites contained too much information related to Geography category compared to other categories (see the extreme left-hand bars of the diagram in Fig. 2). The best coverage in terms of both breadth and depth of detail was demonstrated by A.P.T. dell' Altopiano di Pinè e valle di Cembra. Moreover, this website also largely outnumbered all other sites obtaining a total count of 95 annotations. In comparison, the second best result demonstrated by two websites - of A.P.T. Valle di Fiemme and Ingarda Trentino S.p.a. - was only 49 annotation counts. Therefore, other Tourist Boards could take this result as a best practice example in order to improve their CE.

Table 2. Evaluation summary for the Tourist Board Websites

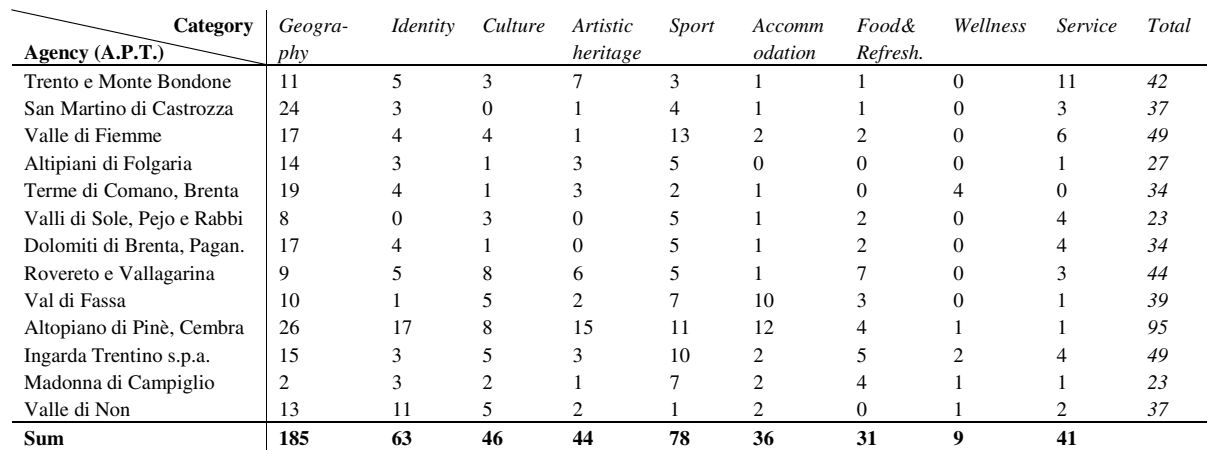

\section{Conclusion}

In this work, we emphasized the need in evaluating $\mathrm{CE}$ of websites. To address this issue, we proposed a systematic approach for estimating a website's CE where the key role is played by its content. Moreover, we suggested a tool to automate this evaluation, i.e., a SA framework Cerno, and showcased our method on a realistic case study. The study was fulfilled for 13 websites of Tourist Boards of the Italian autonomous province Trentino. The results of the study, though carried out using the basic metric for $\mathrm{CE}$, allowed us to identify strong and weak points for each site and derive a number of useful recommendations for improving the communication between providers of tourist services and their target sectors of consumers. These problems were also confirmed after a manual check of the site content.

From an application viewpoint, this case study demonstrates how advances in modern information technologies and, in particular, SA and domain models can yield benefits to both providers and users of tourist services $[12,26]$.

Our future work will address the limitations of the first applications of the method in order to: (a) include a deeper investigation of the $\mathrm{CE}$ testing the metrics introduced in section 2 applying other modules of Cerno [31], so that to analyze the structural information of a document and XML tags [30] (step 6); (b) take into account information contained in multimedia content of websites [17] (step 5); and (b) validate the 
method with different CE metrics on different types of web sites. Furthermore, we are interested in developing a toolset to support construction of a conceptual model (steps 3 and 4). From the research viewpoint, we aim to investigate what types of problems can be identified by applying different CE metrics. This will allow for a fine-tuning of our $\mathrm{CE}$ evaluation method to the conditions or expectations of a particular case study.

Acknowledgments. This work was partially sponsored by the PAPYRUS project (ICT-215874).

\section{References}

1. Austin, J.L.: How to Do Things With Words. Harvard University Press, Cambridge (1962)

2. Chandler, D.: Semiotics: The Basics. Routledge, London (2002)

3. Coulleri, C.: Semantic annotation of websites, Master's thesis, University of Trento (2006)

4. Detagger tool description, http:/ / www . programmi.com/detail.asp? id=6311

5. Doerry, E.: Evaluating distributed environments based on communicative efficacy. In: Katz, I., Mack, R., Marks, L. (eds.) Proc. CHI 1995, pp. 47-48. ACM, New York (1995)

6. eTourism research group, http: / /www. etourism. economia. unitn. it

7. Herrick, J.A.: The History and Theory of Rhetoric. An Introduction. Allyn \& Bacon, Boston (1990)

8. Kiyavitskaya, N., Zeni, N., Cordy, J.R., Mich, L., Mylopoulos, J.: Text Mining through Semi-Automatic Semantic Annotation. In: Reimer, U., Karagiannis, D. (eds.) PAKM 2006. LNCS (LNAI), vol. 4333, pp. 143-154. Springer, Heidelberg (2006)

9. Kiyavitskaya, N., Zeni, N., Cordy, J.R., Mich, L., Mylopoulos, J.: Cerno: Lightweight tool support for semantic annotation of textual documents. Journal of Data and Knowledge Engineering 68(12), 1470-1492 (2009)

10. Lefons, E., Pazienza, M.T., Silvestri, A., Tangorra, F., Corfiati, L., De Giacomo, P.: An algebraic model for systems of psychically interacting subjects. In: Dubuisson, O. (ed.) Proc. IFAC Workshop Information \& Systems, Compiegne, France, pp. 155-163 (1977)

11. Local tourist boards, http://www.visittrentino.it/en/chi_siamo

12. Maedche, A., Staab, S.: Applying Semantic Web Technologies for Tourism Information Systems. In: Wöber, K., Frew, A., Hitz, M. (eds.) 9th Int. Conf. for ICT in Tourism (ENTER 2002), Innsbruck, Austria, pp. 311-319 (2002)

13. Mich, L., Franch, M.: Instantiating Web Sites Quality Models: an Ontologies driven Approach. In: Proc. IWWOST 2005, Porto, Portugal (2005),

http: / / ftp. informatik. rwth-aachen. de/Publications /CEURWS/Vol-153/paper5.pdf

14. Mich, L., Franch, M., Martini, U.: A modular approach to quality evaluation of tourist destination website: The quality model factory. In: Proc. Int. Conf. for ICT in Tourism (ENTER 2005), Innsbruck, Austria, pp. 555-565 (2005)

15. Olsina, L., Rossi, G.: Measuring Web Application Quality with WebQEM. IEEE MultiMedia 9(4) (2002)

16. On-line thesaurus, http: / / thesaurus.reference.com

17. Paci, G., Pedrazzi, G., Turra, R.: Wikipedia based semantic metadata annotation of audio transcripts. In: Proc. of 11th Int. Work. on Image Analysis for Multimedia Interactive Services (WIAMIS). IEEE Computer Society, Los Alamitos (2010)

18. Robbins, S.P.: Organizational Behavior - Concepts, Controversies, Applications, 4th edn. Prentice-Hall, Englewood Cliffs (2004) 
19. Shannon, C.E., Weaver, W.: The Mathematical Theory of Communication. University of Illinois Press, Urbana (1949)

20. Siorpaes, K., Simperl, E.: Human Intelligence in the Process of Semantic Content Creation. In: World Wide Web. Springer, Netherlands (2009)

21. Scott, W.G., Mitchell, T.R.: Organization Theory: a Structural and Behavioural Analysis. Concord, Irwin (1972)

22. Spohrer, J., Riecken, D. (eds.): Introduction to Special issue on Services science. Communications of the ACM 49 (7) (July 2006)

23. Stanca, L.: Information society in Italy (2004) (in Italian), http: //www. innovazione.gov.it/ita/normativa/pubblicazioni/ra pp_stat_04_presentazione.shtml

24. Stuart, H.: Towards a definitive model of the corporate identity management process. Corporate Communications 4(4), 200-207 (1999)

25. Triacca, L., Bolchini, D., Botturi, L., Inversini, A.: MiLE: Systematic Usability Evaluation for E-learning Web Applications ED Media 2004, Lugano, vol. 1, pp. 4398-4405 (2004)

26. Walchhofer, N., Fröschl, K.A., Dippelreiter, B., Pöttler, M., Werthner, H.: Semamo: An Approach to Semantic Market Monitoring. Information Technology \& Tourism 11(3), 197-209 (2009)

27. WebExtractor, http://sourceforge.net/projects/webextractor

28. Winograd, T., Flores, F.: Understanding Computers and Cognition: A New Foundation for Design. Addison-Wesley Professional, Reading (1987)

29. WordNet lexical database, http: / / wordnet.princeton. edu

30. Zeni, N.: The Cerno Framework for Semantic Annotation: Extensions and Applications, $\mathrm{PhD}$ thesis, University of Trento (2008)

31. Zeni, N., Kiyavitskaya, N., Mich, L., Cordy, J.R., Mylopoulos, J.: A lightweight approach to semantic annotation of research papers. In: Kedad, Z., Lammari, N., Métais, E., Meziane, F., Rezgui, Y. (eds.) NLDB 2007. LNCS, vol. 4592, pp. 61-72. Springer, Heidelberg (2007) 